\title{
Trajectory of Left Ventricular Ejection Fraction Among Individuals Eligible for Implantable Cardioverter-Defibrillator
}

\author{
Selma Carlson ${ }^{1}$, Amy Gravely ${ }^{1}$, and Selcuk Adabag ${ }^{2}$ \\ ${ }^{1}$ Minneapolis VA Health Care System \\ ${ }^{2}$ Veterans Administration Hospita, University of Minnesota Medical School
}

July 13, 2020

\begin{abstract}
Objective: Examine the trajectory of left ventricular ejection fraction (EF) among patients eligible for implantable cardioverterdefibrillator (ICD) therapy Background: Ejection fraction is the cornerstone criterion for ICD therapy, but the risk of sudden cardiac death (SCD) remains after an improvement in EF. Methods: We examined the trajectory of EF among 1178 participants of the Sudden Cardiac Death in Heart Failure Trial (SCD-HeFT) who had 3 or more assessments of EF, at least 90 days apart. A follow-up EF $>35 \%$ or $>10 \%$ absolute increase in EF from baseline were examined as the criteria for EF improvement. Results: At first follow-up, 381 (32\%) patients had an improvement of EF to $>35 \%$. However, EF had returned back to ?35\% in $109(27 \%)$ of these patients at second follow-up. Similarly, $446(38 \%)$ patients experienced a $>10 \%$ improvement in EF at first follow-up, but 109 (24\%) of these had a subsequent $>10 \%$ decrease in EF at the second follow-up. Of the 32 patients with normalized $\mathrm{EF}([?] 55 \%)$ at first follow-up, 18 (56\%) had a subsequent $>10 \%$ decrease in EF. The fluctuation in EF was present in both ischemic and non-ischemic cardiomyopathy but a higher proportion of patients with non-ischemic cardiomyopathy had an improvement in EF to $>35 \%$ at first follow-up compared to those with ischemic cardiomyopathy (38\% vs. $27 \%, \mathrm{p}=<0.0001)$. Conclusion: There is substantial fluctuation of EF among patients who are eligible for ICD therapy. These data may help explain the continued risk of SCD after improvement in EF.
\end{abstract}

Trajectory of Left Ventricular Ejection Fraction Among Individuals Eligible for Implantable Cardioverter-Defibrillator

Selma Carlson, $\mathrm{MD}^{1,2}$, Amy Gravely, $\mathrm{MA}^{3}$, and Selçuk Adabag, MD, $\mathrm{MS}^{1,2}$

${ }^{1}$ Division of Cardiology, Minneapolis VA Medical Center, Minneapolis, MN; ${ }^{2}$ Division of Cardiology, Department of Medicine, University of Minnesota, Minneapolis, MN; ${ }^{3}$ Research Service, Minneapolis VA Medical Center, Minneapolis, MN

Word Count : 2631

\section{Conflict of interest:}

Dr. Adabag has received research grants from the American Heart Association and Medtronic.

No other disclosures were reported.

\section{Address for Correspondence}

Selma Carlson, MD

Division of Cardiology (111C)

One Veterans Drive 
Minneapolis, MN 55417

Email: selma.carlson@va.gov

\section{STRUCTURED ABSTRACT}

Objective: Examine the trajectory of left ventricular ejection fraction (EF) among patients eligible for implantable cardioverter-defibrillator (ICD) therapy

Background: Ejection fraction is the cornerstone criterion for ICD therapy, but the risk of sudden cardiac death (SCD) remains after an improvement in EF.

Methods: We examined the trajectory of EF among 1178 participants of the Sudden Cardiac Death in Heart Failure Trial (SCD-HeFT) who had 3 or more assessments of EF, at least 90 days apart. A follow-up $\mathrm{EF}>35 \%$ or $>10 \%$ absolute increase in EF from baseline were examined as the criteria for EF improvement.

Results: At first follow-up, $381(32 \%)$ patients had an improvement of EF to $>35 \%$. However, EF had returned back to [?]35\% in $109(27 \%)$ of these patients at second follow-up. Similarly, $446(38 \%)$ patients experienced a $>10 \%$ improvement in EF at first follow-up, but 109 (24\%) of these had a subsequent $>10 \%$ decrease in EF at the second follow-up. Of the 32 patients with normalized EF ([?]55\%) at first follow-up, $18(56 \%)$ had a subsequent $>10 \%$ decrease in EF. The fluctuation in EF was present in both ischemic and non-ischemic cardiomyopathy but a higher proportion of patients with non-ischemic cardiomyopathy had an improvement in EF to $>35 \%$ at first follow-up compared to those with ischemic cardiomyopathy (38\% vs. $27 \%, \mathrm{p}=<0.0001)$.

Conclusion: There is substantial fluctuation of EF among patients who are eligible for ICD therapy. These data may help explain the continued risk of SCD after improvement in EF.

KEYWORDS : heart failure; ejection fraction; trajectory; implantable cardioverter-defibrillator; EF; ICD; LVEF; cardiomyopathy

\section{INTRODUCTION}

Left ventricular ejection fraction $(\mathrm{EF})$ is the cornerstone of the criteria for implementation of implantable cardioverter-defibrillator (ICD) therapy among patients without a prior cardiac arrest. Individuals with EF [?] $35 \%$ and heart failure symptoms while on optimal medical therapy are eligible for ICD for primary prevention of sudden cardiac death (SCD). ${ }^{1}$ However, approximately $1 / 3^{\text {rd }}$ of the patients with ICD experience an improvement in their EF to $>35 \%$ after implantation..$^{2-6}$ These patients with "recovered EF" have a lower risk of appropriate ICD shocks and SCD than those whose EF remains [?] $35 \%{ }^{2-6}$ However, despite the improvement in EF, some risk of SCD persists.

Previously, in a post-hoc analysis of the Sudden Cardiac Death in Heart Failure Trial (SCD-HeFT) we showed that among patients with recovered EF, where the mean EF increased from $25 \%$ to $45 \%$, ICD therapy was associated with a reduction in all-cause mortality compared to placebo. ${ }^{7}$ To date, this is the only mortality data on the effect of ICD after EF recovery and corroborates the continuing risk of SCD due to ventricular tachyarrhythmias among these patients. One possible explanation for the continuing risk of SCD after the improvement of left ventricular function is the potential for fluctuations in EF that might not have been clinically evident. Indeed, the trajectory of EF among ICD-eligible patients has not been well defined. Thus, the objective of the present study was to examine the trajectory of EF among ICD-eligible patients who participated in the SCD-HeFT.

\section{METHODS}

\section{Data Source}

The Sudden Cardiac Death in Heart Failure Trial enrolled 2,521 patients with ischemic or non-ischemic cardiomyopathy, New York Heart Association (NYHA) class II or III heart failure and an EF [?] 35\% from September 16, 1997 to July 18, 2001. Follow-up ended on October 31, 2003 ${ }^{8}$. After starting vasodilator 
therapy for heart failure, the patients were randomly assigned to placebo $(\mathrm{n}=847)$, amiodarone $(\mathrm{n}=845)$, or single-lead, shock-only, ICD (n=829). After 46 months of follow-up, there was a $23 \%$ reduction of all-cause mortality among patients assigned to ICD in comparison to those assigned to placebo or amiodarone. ${ }^{8}$

Ischemic cardiomyopathy was defined as decreased left ventricular systolic function with either a documented history of myocardial infarction or $>75 \%$ stenosis of a major coronary artery. Non-ischemic cardiomyopathy was defined as decreased left ventricular systolic function without a flow-limiting stenosis. A detailed review of SCD-HeFT methods has been published previously. ${ }^{9}$

For the present analysis, a de-identified, publicly-available version of the SCD-HeFT database was accessed through the NHLBI Biorepository program BioLINCC. ${ }^{10}$ This study met the criteria for exempt status after evaluation by the Institutional Review Board at our institution.

\section{Study patients}

Participants of SCD-HeFT who had 3 or more assessments of EF, at least 90 days apart were included in the current analysis (Figure 1). While the baseline, qualifying assessment of EF was necessary to participate in the SCD-HeFT, the subsequent EF assessments were not mandated by the study protocol. ${ }^{9}$ The average number of EF assessments per person was 2.40. Of the 2521 participants of the SCD-HeFT, 1310 had 2, and 1211 had 3 or more EF measurements. Of the 1211 patients with 3 or more EF measurements, 33 were excluded from the current analysis because they had $<90$ days between EF 1 and EF $2(n=6)$ or between EF 2 and EF $3(\mathrm{n}=27)$. Thus, total sample size for this analysis was 1178 (Figure 1).

\section{EF assessment}

The SCD-HeFT protocol did not mandate a specific modality to measure EF. While the majority of patients had EF measured by echocardiogram $(\mathrm{n}=1461)$, some were measured by radionuclide angiography $(\mathrm{n}=616)$, and others by contrast angiography $(\mathrm{n}=436)$. Studies were interpreted at their respective enrollment centers.

\section{Statistical Analysis}

For descriptive analysis, we compared the baseline characteristics of the patients who had 3 or more EF measurements versus fewer than 3 measurements. Normally-distributed continuous variables were compared with t-test. Categorical variables were compared with chi-square test.

We categorized the study population into two groups based on whether their follow-up EF measurements were $>35 \%$ or [?] $35 \%$. Subgroup analyses were performed among patients with ischemic and non-ischemic cardiomyopathy and those with normalized EF. In additional analyses, we also categorized the study population into three groups based on their follow-up EF measurements. Patients who had a $>10 \%$ increase in EF were categorized as improved, those with a $>10 \%$ decrease in EF were categorized as reduced, and patients with $<10 \%$ change in EF in either direction were categorized as unchanged. We performed sensitivity analyses using $>5 \%$ cutoff instead of $10 \%$. Unadjusted logistic regression was used to comparing ischemic and non-ischemic proportions at first follow up. All analyses were performed using SAS (SAS Institute) version 9.4. A p value $<0.05$ was accepted as significant.

\section{RESULTS}

\section{Patient Characteristics}

The baseline characteristics of the 1,178 patients with 3 or more EF measurements, who were included in this analysis, are shown in Tables 1 and 2. Compared to those without EF recovery, those with improvement in EF were more likely to be female, have non-ischemic cardiomyopathy, a QRS duration $<120 \mathrm{~ms}$ and a more recent heart failure diagnosis (Tables 1 and 2).

\section{Trajectory of EF measurements}

The mean (+-SD) time from enrollment to first follow-up EF was 0.99 (+-0.24) years and from first to second follow-up EF was 1.39 (+-0.43) years. The mean EF was $24.5 \%(+-6.7)$ at baseline, $31.7 \%(+-11.5)$ at first 
follow-up and $32.6 \%(+-12.6)$ at second follow-up. There was no significant difference in mean EF between ischemic and non-ischemic patients at baseline, first follow-up and second follow-up.

EF cut-off at $35 \%$

While all patients had an EF [?] 35\% at baseline, $381(32 \%)$ had an improvement to $>35 \%$ at first follow-up (Figure 1). However, at second follow-up EF had returned back to [?]35\% in 104 (27\%) of these patients. On the other hand, of the 797 patients who had an EF $<35 \%$ at first follow-up, 146 (18\%) had an improvement to $>35 \%$ at the second follow-up. A fluctuation was observed in both the ischemic and non-ischemic cardiomyopathy subgroups (Appendix), but a higher proportion of patients with non-ischemic cardiomyopathy had an improvement in EF to $>35 \%$ at first follow-up compared to those with ischemic cardiomyopathy (38\% vs. $27 \%, \mathrm{p}=<0.0001)$.

\section{Greater than $10 \%$ change in $\mathrm{EF}$}

Using a $>10 \%$ change in EF as a clinically meaningful cutoff, 446 patients (38\%) had an increase, $683(58 \%)$ were unchanged, and 49 (4\%) had a decrease in EF at first follow-up (Figure 2). Of the 446 patients who experienced an increase in EF at first follow-up, 109 (24\%) had a >10\% decrease at the second follow-up (Figure 2). On the other hand, of the 49 patients who experienced a decrease in EF at first follow-up, 16 (33\%) had an increase at second follow-up (Figure 2). While a fluctuation in EF was present in both the ischemic and non-ischemic cardiomyopathy subgroups (Appendix), a larger proportion of the patients with non-ischemic cardiomyopathy had an increase in EF at first follow-up than those with ischemic cardiomyopathy (44\% vs. $32 \%, \mathrm{p}<0.0001)$. The results were similar in sensitivity analysis using $>5 \%$ change as the cut-off.

\section{Normalized EF}

A total of 32 patients (3\%) had normalized EF ([?] 55\%) at the first follow-up. The mean EF for these people increased to $61.58 \%$ (+- 4.19). These patients predominantly had non-ischemic cardiomyopathy $(\mathrm{n}=27 ; 84 \%)$. However, $18(56 \%)$ of these patients had a subsequent, $>10 \%$ decrease in EF.

\section{DISCUSSION}

This study demonstrates that a considerable fluctuation of EF occurs among patients with EF [?] 35\%, changing their ICD eligibility status over time. After one year, almost $40 \%$ of patients with EF [?] $35 \%$ experienced a $>10 \%$ improvement in EF. But over the next 1.4 years, approximately $25 \%$ of those who had an improvement in EF lost their gains returning back to EF [?]35\%. While the fluctuation in EF was present in both ischemic and non-ischemic cardiomyopathy, a larger proportion of those with non-ischemic cardiomyopathy had an improvement in EF and a lower proportion had subsequent reduction. These results may explain the root cause of continued SCD risk after EF improvement.

Several previous studies have shown that $30-40 \%$ of patients with ICD experience a substantial improvement in EF post-implantation. Our results support these previous observations. ${ }^{2-4}$ Presumed to be from continued medical therapy, improvement in EF was associated with a lower incidence of appropriate ICD therapy in comparison to those whose EF did not change. ${ }^{1,3-6}$ Similar observations were also made among patients with cardiac resynchronization therapy, suggesting that EF improvement is associated with better outcomes regardless of its etiology. ${ }^{11}$ These studies raised the question of whether ICD generator should be replaced at the end of battery life among patients with EF improvement.

Recently, in a post hoc analysis of SCD-HeFT we demonstrated that patients with a substantial improvement in EF appeared to have a similarsurvival benefit from ICD in comparison to those who did not demonstrate EF improvement. ${ }^{7}$ To date, this is the only comparison of survival in relation to ICD among patients with $\mathrm{EF}$ improvement. The results from the present investigation suggest that recurrence of cardiomyopathy among patients with recovered EF may be the culprit for the continued benefit of ICD among these patients. Cumulatively these results support ICD generator replacement at the end of battery life regardless of EF. 
Recently, Lupon et al. examined the prognostic impact of the dynamic changes in EF over a 15-year followup in a prospective, consecutive, observational registry of outpatient heart failure patients. ${ }^{12}$ They found that the majority of patients had a marked rise in EF during the first year, maintained up to a decade, followed by a slow EF decline thereafter. Our findings add to this literature by showing that fluctuation in EF around the cut-off 35\% may influence clinical decisions on ICD therapy. The present data also showed that while the mean EF was stable between the $1^{\text {st }}$ and $2^{\text {nd }}$ follow-up (31.7\% vs. 32.6, respectively). there remained significant fluctuation in $\sim 25 \%$ of the cohort, which had potential treatment implications for those patients.

Patients with non-ischemic cardiomyopathy were more likely to experience an improvement in EF in this and previous cohorts. ${ }^{2,3,12}$ Absence of large myocardial scar volume may be responsible from this observation. ${ }^{12,13}$ Lupon and colleagues showed that while ischemic heart failure patients showed a modest EF increase during the first year of medical therapy those with non-ischemic heart failure had a more pronounced improvement. ${ }^{12}$ Further, those with non-ischemic heart failure had a more prolonged increase during follow-up after one year than ischemic heart failure patients. ${ }^{12}$ Collectively, these results may help us understand the lack of survival improvement with ICD therapy among patients with non-ischemic cardiomyopathy. ${ }^{14,15}$

While medical therapy for heart failure is responsible for improvement in EF, less is known about factors that lead to re-worsening of EF after an improvement. Recently, the TRED-HF study examined whether patients with dilated cardiomyopathy could discontinue heart failure medications after recovery of cardiac function, which was defined as being asymptomatic, EF increasing from $<40 \%$ to $>50 \%$, normalization of left ventricular end diastolic volume, and decreasing of N-terminal pro-B-type natriuretic peptide to $<250$ ng/L. ${ }^{16}$ These researchers found that cardiomyopathy relapsed in $44 \%$ of the patients following withdrawal of medical therapy versus in no patients who continued heart failure medications, suggesting that heart failure treatment should be continued indefinitely. ${ }^{16}$ Our analysis adds to these data by showing that EF trajectory may be volatile even with continued medical therapy.

Patients with normalization of EF constitute a special subgroup. Based on limited data the risk of appropriate ICD therapy is very low in these patients. ${ }^{4,11}$ However, in a small prospective study, Cioffi et al. showed EF normalization to be a transient finding in $55 \%$ of their patients, with the effect lasting a mean duration of $15+-5$ months. ${ }^{17}$ In our study, only $3 \%$ of patients experienced a rise in EF to $>55 \%$. Similar to the Cioffi study, $56 \%$ of our patients had a subsequent drop in EF of $>10 \%$. This suggests that normalization of EF is not equivalent to a cure of $\mathrm{HF}$, but rather remission as a significant proportion of these patients remain at risk for relapse and SCD. ${ }^{18-20}$

\section{Limitations}

This post-hoc analysis of prospectively-collected data has several limitations. First, serial measurement of EF was not dictated by the protocol. However, nearly $50 \%$ of the SCD-HeFT participants had 3 or more EF measurements. These patients were in general healthier than the rest of the cohort, who may not have exhibited as much improvement in EF. Second, the modality used for EF assessment was not standardized and the studies were interpreted locally at the enrolling institution. Thus, observed changes in EF may be partially be due to variability in modalities or reader, which has been shown to be present between different modalities even with standardized core lab measurements. ${ }^{21}$ However, these results reflect realworld practice and our observation of EF improvement in nearly $40 \%$ of patients is replicated consistently by observations from smaller, single-center studies. ${ }^{2-4,6}$ Finally, optimal medical therapy for heart failure has evolved considerably since 2005 when, SCD-HeFT trial was published. However, EF improvement in $30-40 \%$ of ICD patients was replicated in past as well as contemporary cohorts. Whether fluctuation in EF also occurs in contemporary cohorts needs to be studied.

\section{CONCLUSION}

Substantial fluctuations of EF occur among patients with ischemic or non-ischemic cardiomyopathy who are eligible for ICD implantation. These data suggest that EF improvement in these patients represents remission rather than true recovery of the cardiomyopathy and may help explain the continued risk of SCD 
after improvement in EF. These data support the need for indefinite medical and continued device therapy after improvement in EF.

Figure 1 - Sankey chart showing study patient who experienced an increase of EF to $>35 \%$ by the $2^{\text {nd }}$ follow up.

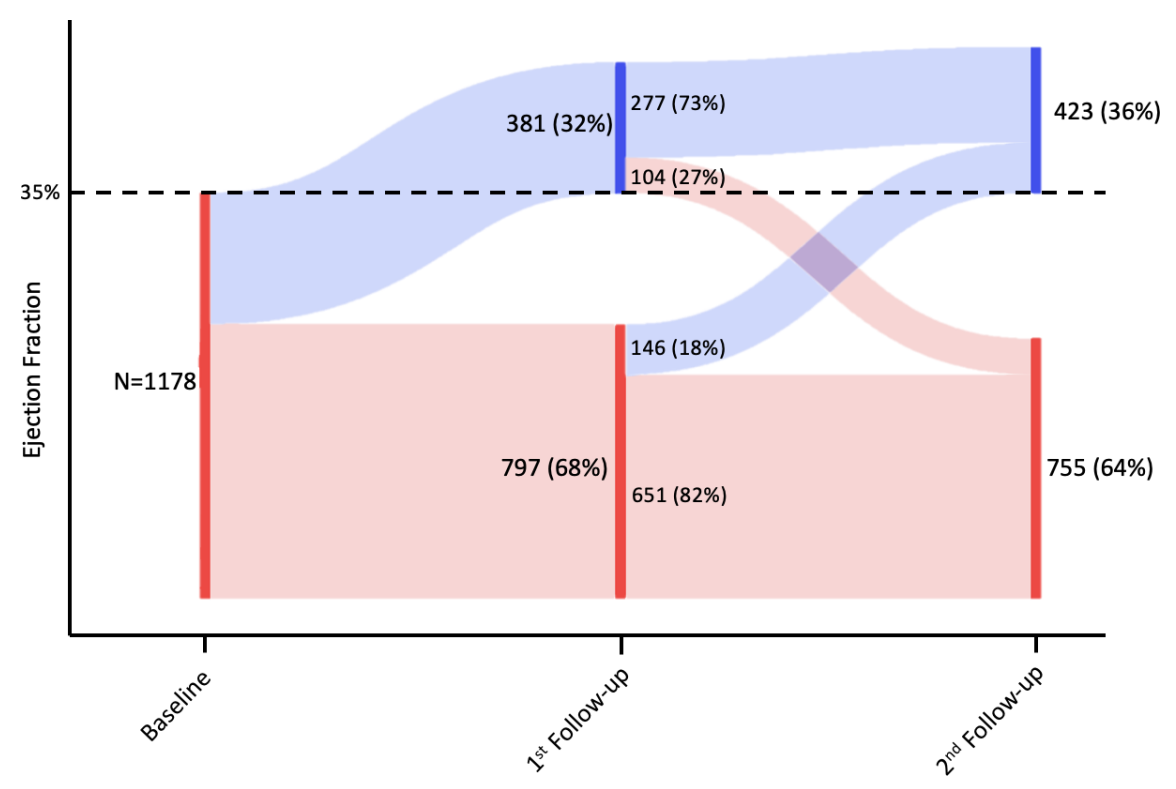

Figure 2 - Sankey chart showing EF trajectories based on $>10 \%$ absolute improvement or reduction in EF at first and second follow-up.

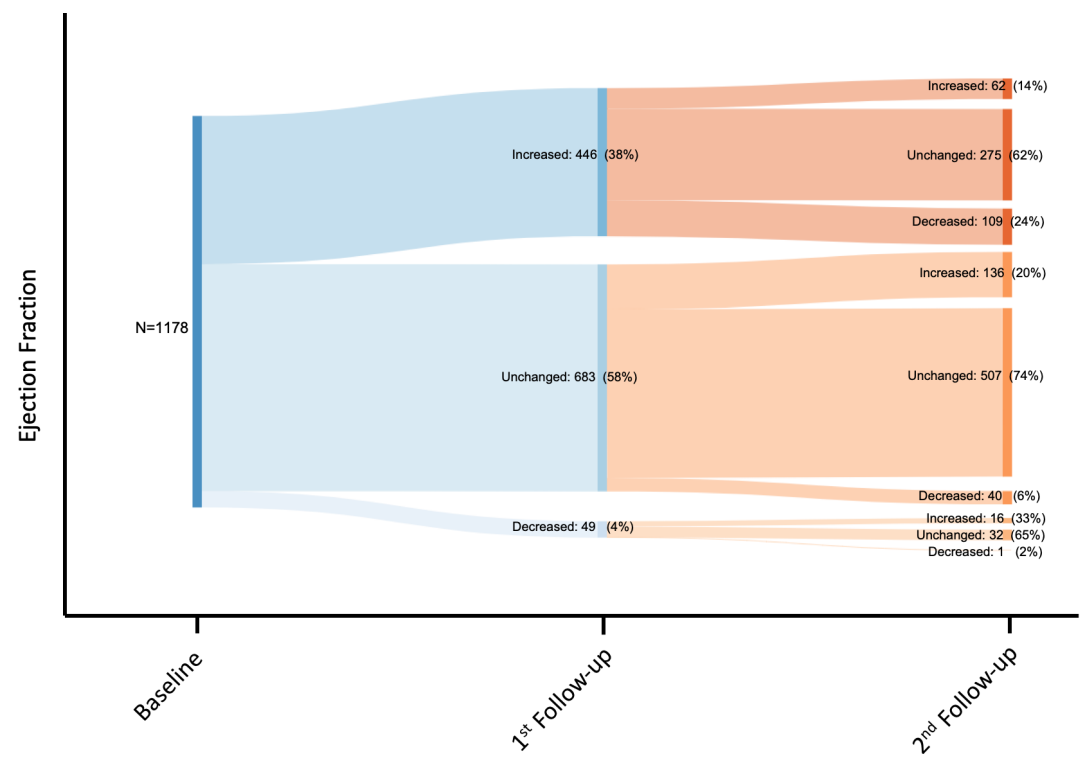

TABLE 1. Characteristics of patients whose EF increased to $>35 \%$ by the $2^{\text {nd }}$ follow up versus those who did not. 


\begin{tabular}{|c|c|c|c|c|}
\hline Variable & $\begin{array}{l}\text { Total study } \\
\text { population } \\
\mathrm{N}=1178\end{array}$ & $\begin{array}{l}\mathrm{EF}[?] 35 \% \\
\mathrm{~N}=755\end{array}$ & $\begin{array}{l}\mathrm{EF}>35 \% \\
\mathrm{~N}=423\end{array}$ & P-Value \\
\hline Age, years & $58.3(11.6)$ & $58.2(11.5)$ & $58.4(11.7)$ & 0.7920 \\
\hline Male & $889(75.5)$ & $594(78.7)$ & $295(69.7)$ & 0.0006 \\
\hline Caucasian & $962(81.7)$ & $613(81.2)$ & $349(82.5)$ & 0.5761 \\
\hline Medical History & & & & \\
\hline Non-ischemic CM & $585(49.7)$ & $338(44.8)$ & $247(58.4)$ & $<0.0001^{\mathrm{a}}$ \\
\hline NYHA Class III & $301(25.6)$ & $199(26.4)$ & $102(24.1)$ & 0.3969 \\
\hline Baseline EF, \% & $24.5(6.7)$ & $23.4(6.7)$ & $26.5(6.3)$ & $<0.0001^{b}$ \\
\hline $\begin{array}{l}\text { Pulmonary } \\
\text { disease }\end{array}$ & $195(16.6)$ & $120(15.9)$ & $75(17.7)$ & 0.4159 \\
\hline Never smoker & $315(26.7)$ & $193(25.6)$ & $122(28.8)$ & 0.4230 \\
\hline Hyperlipidemia & $645(54.8)$ & $433(57.4)$ & $212(50.1)$ & 0.0167 \\
\hline Hypertension & $610(51.8)$ & $375(49.7)$ & $235(55.6)$ & 0.0524 \\
\hline Stroke & $65(5.5)$ & $43(5.7)$ & $22(5.2)$ & 0.7214 \\
\hline Diabetes & $316(26.8)$ & $191(25.3)$ & $125(29.6)$ & 0.1140 \\
\hline NSVT & $236(20.0)$ & $156(20.7)$ & $80(18.9)$ & 0.4717 \\
\hline Syncope & $87(7.4)$ & $57(7.55)$ & $30(7.1)$ & 0.7733 \\
\hline $\begin{array}{l}\text { QRS duration } \\
<120 \mathrm{~ms}\end{array}$ & $691(58.7)$ & $388(51.4)$ & $303(71.6)$ & $<0.0001^{a}$ \\
\hline $\begin{array}{l}\text { Atrial fibrillation } \\
\text { by ECG }\end{array}$ & $71(6.0)$ & $40(5.3)$ & $31(7.33)$ & 0.1601 \\
\hline $\begin{array}{l}\text { Blood pressure - } \\
\text { diastolic, } \mathrm{mmHg}\end{array}$ & $71.3(11.1)$ & $71.0(10.9)$ & $71.9(11.3)$ & 0.1893 \\
\hline $\begin{array}{l}\text { Blood pressure - } \\
\text { systolic, } \mathrm{mmHg}\end{array}$ & $120.3(19.5)$ & $118.7(18.2)$ & $123.3(21.2)$ & 0.0001 \\
\hline Pulse, beats/min & $74.0(14.1)$ & $73.8(13.8)$ & $74.4(14.7)$ & 0.4716 \\
\hline Sodium, mg/dl & $139.3(3.1)$ & $139.3(3.1)$ & $139.4(3.0)$ & 0.5656 \\
\hline $\begin{array}{l}\text { Potassium, } \\
\mathrm{mEq} / \mathrm{L}\end{array}$ & $4.4(0.5)$ & $4.4(0.5)$ & $4.4(0.4)$ & 0.5656 \\
\hline Ace inhibitor & $992(84.2)$ & $638(84.5)$ & 354 (83.7) & 0.7127 \\
\hline Beta blocker & $817(69.4)$ & $522(69.1)$ & $295(69.7)$ & 0.8301 \\
\hline Digoxin & $802(68.1)$ & $533(70.6)$ & $269(63.6)$ & 0.0134 \\
\hline Diuretic (loop) & $936(79.5)$ & $600(79.5)$ & $336(79.4)$ & 0.9878 \\
\hline Spironolactone & $202(17.2)$ & $125(16.6)$ & $77(18.2)$ & 0.4718 \\
\hline Statins & $487(41.3)$ & $328(43.4)$ & $159(37.6)$ & 0.0503 \\
\hline Months from & $40.0(47.5)$ & $43.7(47.5)$ & $33.49(46.9)$ & 0.0004 \\
\hline
\end{tabular}

Continuous variables are represented as mean $( \pm \mathrm{SD})$; categorical variables as $\mathrm{n}(\%)$

Abbreviations: EF - ejection fraction, CM - cardiomyopathy, NYHA - New York Heart Association,

NSVT - non-sustained ventricular tachycardia, ECG - electrocardiogram, CHF - congestive heart failure

TABLE 2. Characteristics of patients whose EF increased at least $10 \%$ by the $2^{\text {nd }}$ follow up versus those who did not.

\begin{tabular}{llll}
\hline Variable & $\begin{array}{l}\text { Patients without 10\% } \\
\text { increase } \mathbf{N}=\mathbf{7 0 5}\end{array}$ & $\begin{array}{l}\text { Patients with 10\% } \\
\text { increase N=473 }\end{array}$ & P-Value \\
Age, years & $58.5(11.6)$ & $58.0(11.6)$ & 0.5592
\end{tabular}




\begin{tabular}{llll} 
Male & $558(79.2)$ & $331(70.0)$ & 0.0003 \\
Caucasian & $578(82.0)$ & $384(81.2)$ & 0.7273 \\
Medical History & & & \\
Non-ischemic CM & $319(45.3)$ & $266(56.2)$ & 0.0002 \\
NYHA Class III & $184(26.1)$ & $117(24.7)$ & 0.5989 \\
Baseline EF, \% & $26.54(6.3)$ & $23.39(6.7)$ & $<0.0001$ \\
Pulmonary disease & $110(15.6)$ & $85(18.0)$ & 0.2838 \\
Never smoker & $185(26.2)$ & $130(27.5)$ & 0.7367 \\
Hyperlipidemia & $403(57.2)$ & $242(51.2)$ & 0.0425 \\
Hypertension & $365(51.8)$ & $245(51.8)$ & 0.9936 \\
Stroke & $42(5.96)$ & $23(4.86)$ & 0.4198 \\
Diabetes & $192(27.2)$ & $124(26.2)$ & 0.6989 \\
NSVT & $146(20.7)$ & $90(19.0)$ & 0.4796 \\
Syncope & $57(8.09)$ & $30(6.3)$ & 0.2623 \\
QRS duration $<120$ ms & $326(46.2)$ & $161(34.0)$ & $<0.0001$ \\
Atrial fibrillation by & $36(5.11)$ & $35(7.4)$ & 0.1050 \\
ECG & & $72.01(11.6)$ & 0.0806 \\
Blood pressure - & $70.86(10.7)$ & & \\
diastolic, mmHg & & $122.0(19.6)$ & 0.0187 \\
Blood pressure - & $119.3(19.30)$ & & \\
systolic, mmHg & & $75.10(14.4)$ & 0.0272 \\
Pulse, beats/min & $73.25(13.9)$ & $139.3(3.0)$ & 0.9226 \\
Sodium, mg/dl & $139.3(3.1)$ & $4.4(0.4)$ & 0.5401 \\
Potassium, mEq/L & $4.4(0.5)$ & $396(83.7)$ & 0.7058 \\
Ace inhibitor & $596(84.5)$ & $314(66.4)$ & 0.0701 \\
Beta blocker & $503(71.4)$ & $312(66.0)$ & 0.2012 \\
Digoxin & $490(69.5)$ & $370(78.2)$ & 0.3911 \\
Diuretic (loop) & $566(80.3)$ & $85(18.0)$ & 0.5395 \\
Spironolactone & $117(16.6)$ & $180(38.1)$ & 0.0606 \\
Statins & $307(43.6)$ & & \\
Months from CHF & $45.11(50.1)$ & & \\
diagnosis & & & \\
\hline
\end{tabular}

Continuous variables are represented as mean $( \pm \mathrm{SD})$; categorical variables as $\mathrm{n}(\%)$

Abbreviations: EF - ejection fraction, CM - cardiomyopathy, NYHA - New York Heart Association,

NSVT - non-sustained ventricular tachycardia, ECG - electrocardiogram, CHF - congestive heart failure

ACKNOWLEDGEMENTS We are grateful to the SCD-HeFT trial investigators and to NHLBI BioLINCC for the oppc

\section{REFERENCES:}

1. Al-Khatib Sana M., Stevenson William G., Ackerman Michael J., Bryant William J., Callans David J., Curtis Anne B., et al. 2017 AHA/ACC/HRS Guideline for management of patients with ventricular arrhythmias and the prevention of sudden cardiac death. Circulation. 2018 Sep 25;138(13):e272-391.

2. Naksuk N, Saab A, Li J-M, Florea V, Akkaya M, Anand IS, et al. Incidence of appropriate shock in implantable cardioverter-defibrillator patients with improved ejection fraction. J Card Fail. 2013 Jun;19(6):426-30.

3. Kini V, Soufi MK, Deo R, Epstein AE, Bala R, Riley M, et al. Appropriateness of primary prevention 
implantable cardioverter-defibrillators at the time of generator replacement. J Am Coll Cardiol. 2014 Jun 10;63(22):2388-94.

4. Zhang Y, Guallar E, Blasco-Colmenares E, Butcher B, Norgard S, Nauffal V, et al. Changes in follow-up left ventricular ejection fraction associated with outcomes in primary prevention ICD and CRT-D recipients. J Am Coll Cardiol. 2015 Aug 4;66(5):524-31.

5. Vakil K, Florea V, Koene R, Kealhofer JV, Anand I, Adabag S. Effect of Coronary Artery Bypass Grafting on Left Ventricular Ejection Fraction in Men Eligible for Implantable Cardioverter-Defibrillator. Am J Cardiol. 2016 Mar 15;117(6):957-60.

6. Madhavan M, Waks JW, Friedman PA, Kramer DB, Buxton AE, Noseworthy PA, et al. Outcomes After Implantable Cardioverter-Defibrillator Generator Replacement for Primary Prevention of Sudden Cardiac Death. Circ Arrhythm Electrophysiol. 2016 Mar;9(3):e003283.

7. Adabag S, Patton KK, Buxton AE, Rector TS, Ensrud KE, Vakil K, et al. Association of implantable cardioverter defibrillators with survival in patients with and without improved ejection fraction. JAMA Cardiol. 2017 Jul;2(7):767-74.

8. Bardy GH, Lee KL, Mark DB, Poole JE, Packer DL, Boineau R, et al. Amiodarone or an implantable cardioverter-defibrillator for congestive heart failure. N Engl J Med. 2005 Jan 20;352(3):225-37.

9. Bardy G, Lee K, Mark D, Poole J, Fishbein D. The Sudden Cardiac Death-Heart Failure Trial (SCDHeFT). In: In: Woosley RL, Singh SN, editors Arrhythmia Treatment and Therapy: Evaluation of Clinical Trial Evidence. New York: Marcel Dekker; 2000. p. 323-42.

10. BioLINCC - Biologic Specimen and Data Repository Information Coordinating Center [Internet]. [cited 2020 Mar 8]. Available from: https://biolincc.nhlbi.nih.gov/home/

11. Ruwald Martin H., Solomon Scott D., Foster Elyse, Kutyifa Valentina, Ruwald Anne-Christine, Sherazi Saadia, et al. Left Ventricular Ejection Fraction Normalization in Cardiac Resynchronization Therapy and Risk of Ventricular Arrhythmias and Clinical Outcomes. Circulation. 2014 Dec 1;130(25):2278-86.

12. Lupón J, Gavidia-Bovadilla G, Ferrer E, de Antonio M, Perera-Lluna A, López-Ayerbe J, et al. Dynamic trajectories of left ventricular ejection fraction in heart failure. J Am Coll Cardiol. 2018 Aug;72(6):591-601.

13. Gulati A, Jabbour A, Ismail TF, Guha K, Khwaja J, Raza S, et al. Association of fibrosis with mortality and sudden cardiac death in patients with nonischemic dilated cardiomyopathy. JAMA. 2013 Mar 6;309(9):896-908.

14. Anantha Narayanan M, Vakil K, Reddy YN, Baskaran J, Deshmukh A, Benditt DG, et al. Efficacy of Implantable Cardioverter-Defibrillator Therapy in Patients With Nonischemic Cardiomyopathy: A Systematic Review and Meta-Analysis of Randomized Controlled Trials. JACC Clin Electrophysiol. 2017;3(9):962-70.

15. Køber L, Thune JJ, Nielsen JC, Haarbo J, Videbæk L, Korup E, et al. Defibrillator Implantation in Patients with Nonischemic Systolic Heart Failure. N Engl J Med. 2016 29;375(13):1221-30.

16. Halliday BP, Wassall R, Lota AS, Khalique Z, Gregson J, Newsome S, et al. Withdrawal of pharmacological treatment for heart failure in patients with recovered dilated cardiomyopathy (TRED-HF): an open-label, pilot, randomised trial. Lancet Lond Engl. 2019 Jan 5;393(10166):61-73.

17. Cioffi G, Stefenelli C, Tarantini L, Opasich C. Chronic left ventricular failure in the community: prevalence, prognosis, and predictors of the complete clinical recovery with return of cardiac size and function to normal in patients undergoing optimal therapy. J Card Fail. 2004 Jun;10(3):250-7.

18. Adabag S, Smith LG, Anand IS, Berger AK, Luepker RV. Sudden cardiac death in heart failure patients with preserved ejection fraction. J Card Fail. 2012 Oct;18(10):749-54. 
19. Adabag S, Langsetmo L. Sudden cardiac death risk prediction in heart failure with preserved ejection fraction. Heart Rhythm. 2020 Mar;17(3):358-64.

20. Adabag S, Rector TS, Anand IS, McMurray JJ, Zile M, Komajda M, et al. A prediction model for sudden cardiac death in patients with heart failure and preserved ejection fraction. Eur J Heart Fail. 2014 Nov;16(11):1175-82.

21. Pellikka PA, She L, Holly TA, Lin G, Varadarajan P, Pai RG, et al. Variability in Ejection Fraction Measured By Echocardiography, Gated Single-Photon Emission Computed Tomography, and Cardiac Magnetic Resonance in Patients With Coronary Artery Disease and Left Ventricular Dysfunction. JAMA Netw Open. 2018 03;1(4):e181456.

\section{APPENDIX}

Figure A.1 - Sankey chart showing ICM study patients who experienced an increase of EF to $>35 \%$ by the $2^{\text {nd }}$ follow up.

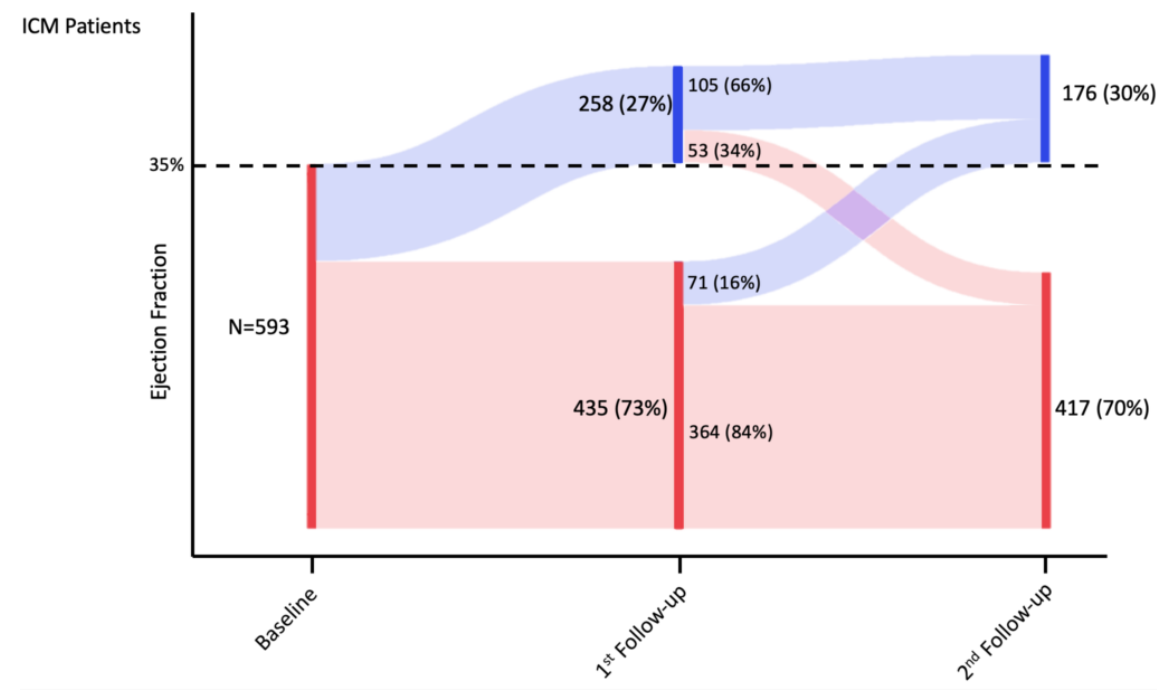

Figure A.2 - Sankey chart showing NICM study patients who experienced an increase of EF to $>35 \%$ by the $2^{\text {nd }}$ follow up. 


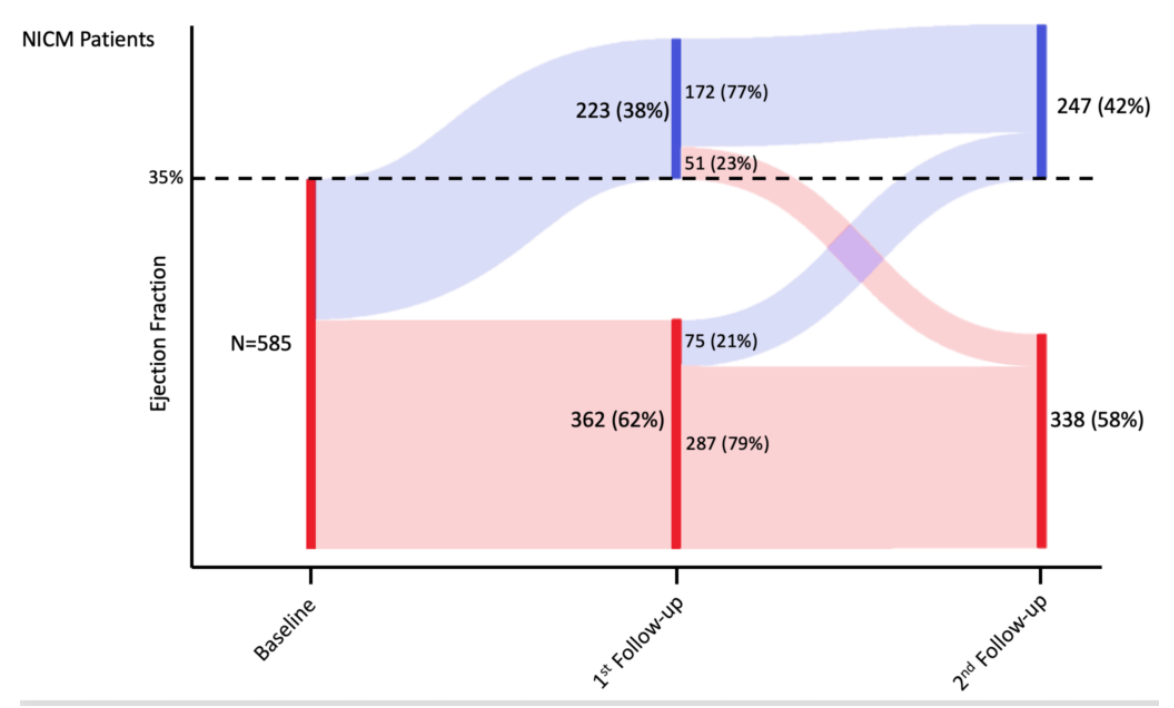

Figure B.1 - Sankey chart showing EF trajectories based on $>10 \%$ absolute improvement or reduction in EF at first and second follow-up in ICM patients

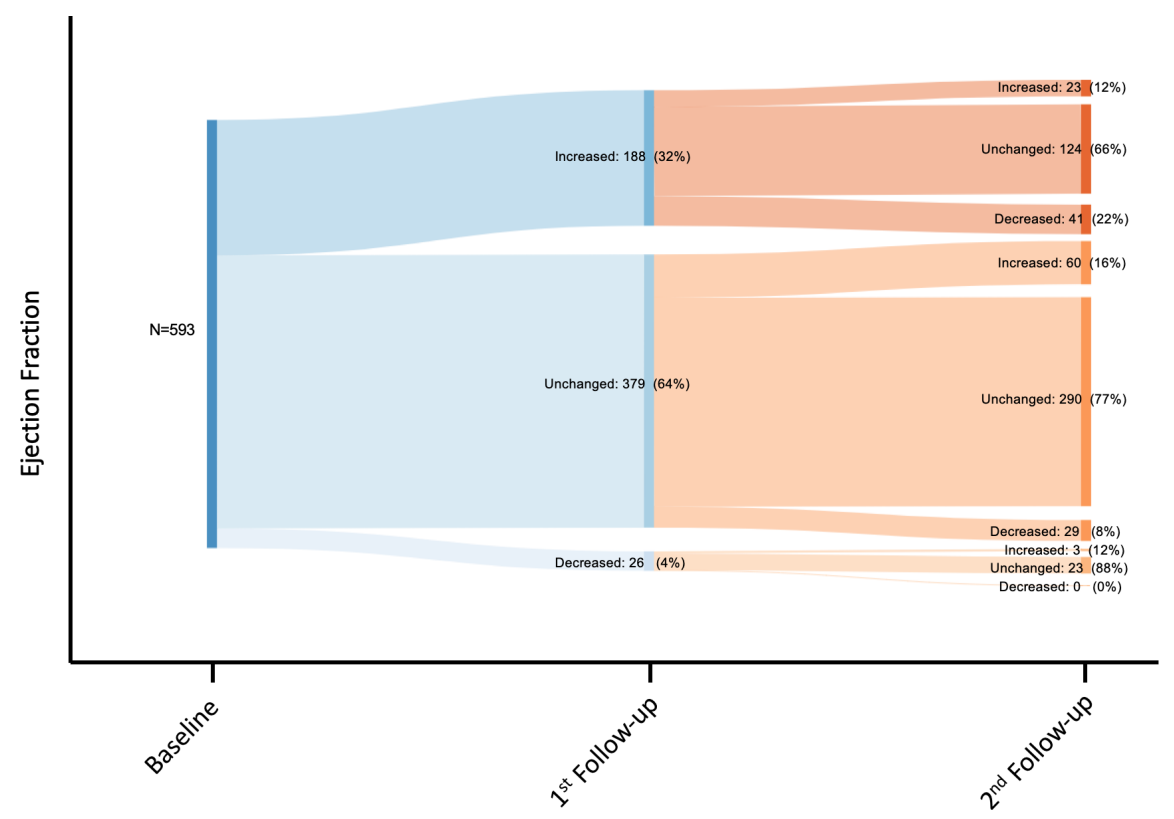

Figure B.2 - Sankey chart showing EF trajectories based on $>10 \%$ absolute improvement or reduction in EF at first and second follow-up in NICM patients 


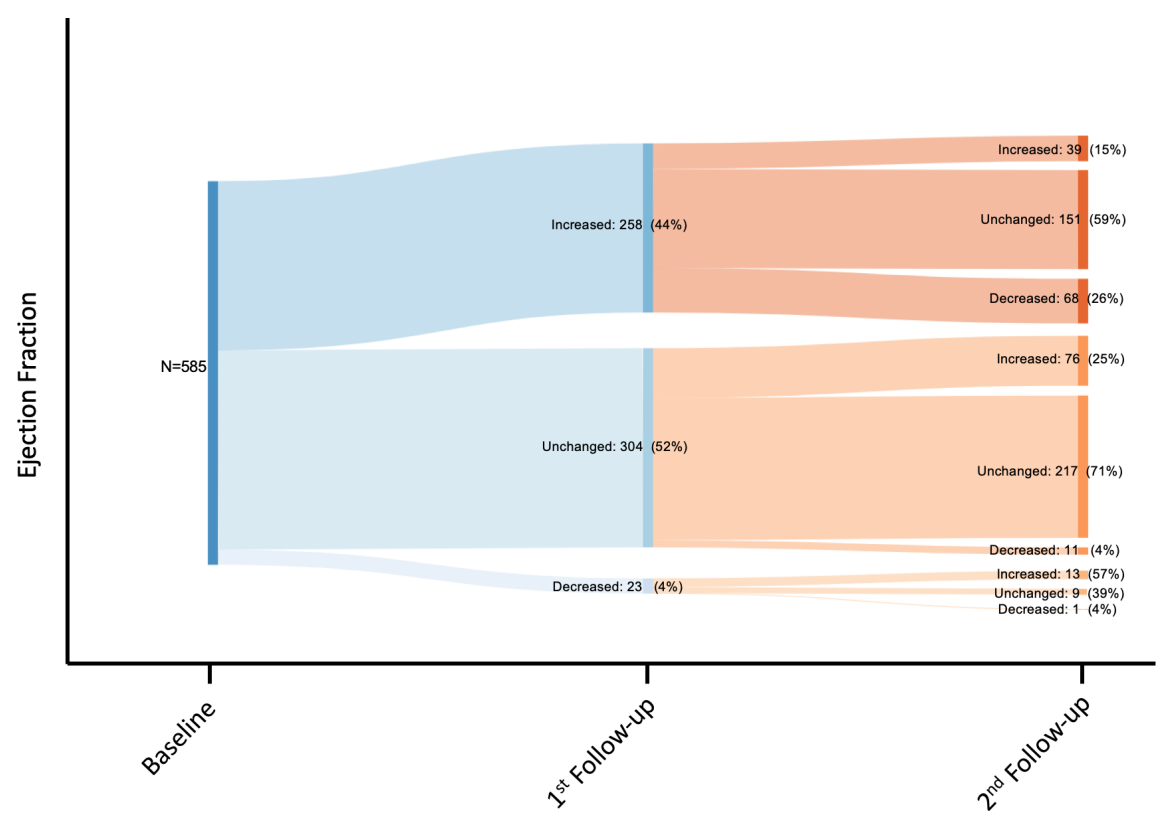

\section{Figure $\mathbf{C}$}

Flowchart documenting SCD-HeFT patient selection criteria

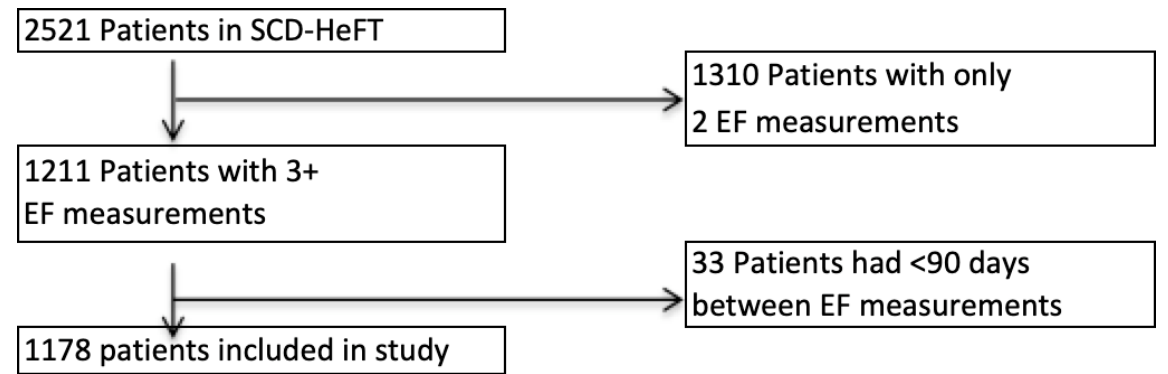

\section{Figure D}

Mean EF $( \pm \mathrm{SD})$ of the patients with ischemic cardiomyopathy (ICM) or non-ischemic cardiomyopathy (NICM) at baseline, first follow-up, and second follow-up. 


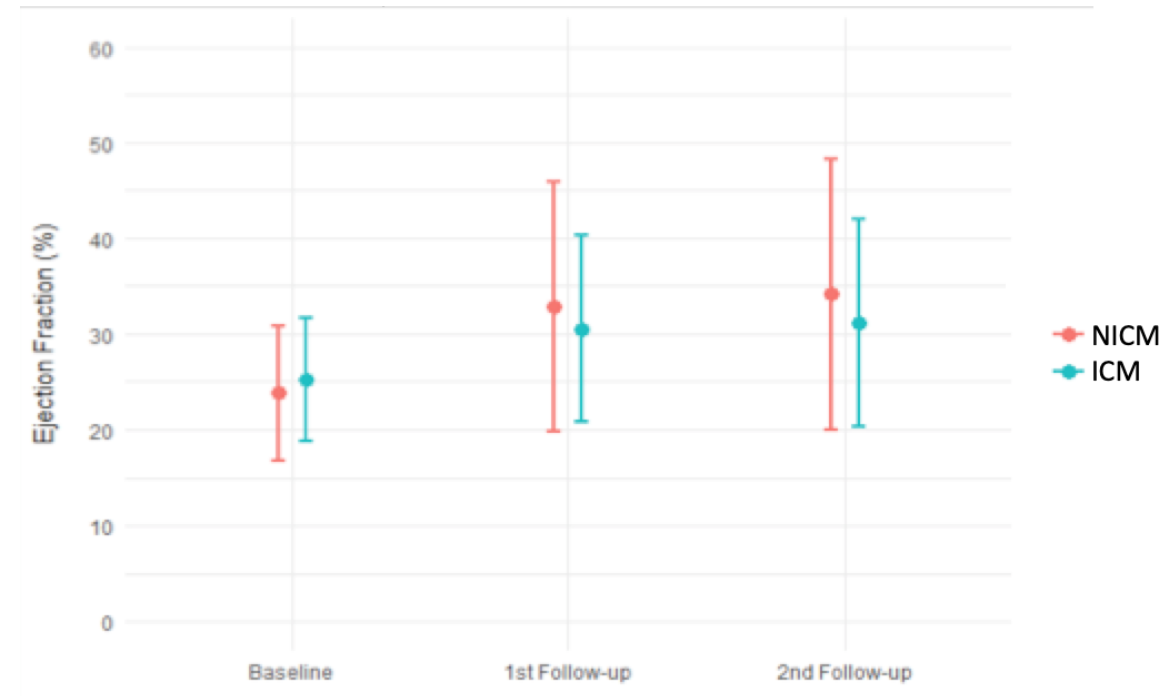

Table A.1 - Characteristics of all patients and those with three or more EF measurements with >90 days in between each measurement - All SCD-HeFT Database Patients

\begin{tabular}{|c|c|c|c|c|}
\hline Variable & $\begin{array}{l}\text { Total SCD-HeFT } \\
\text { cohort } \mathrm{N}=2521\end{array}$ & $\begin{array}{l}{[?] 3 \mathrm{EF}} \\
\text { measurement } \\
\mathrm{N}=1178\end{array}$ & $\begin{array}{l}<3 \mathrm{EF} \\
\text { measurement } \\
\mathrm{N}=1343\end{array}$ & P-Value \\
\hline Age, years & $59.0(11.9)$ & $58.3(11.6)$ & $59.7(12.2)$ & 0.0031 \\
\hline Male & $1,933(76.7)$ & $889(75.5)$ & $1,044(77.7)$ & 0.1788 \\
\hline $\begin{array}{l}\text { Caucasian } \\
\text { Medical History }\end{array}$ & $1,932(76.6)$ & $962(81.7)$ & $970(72.2)$ & $<0.0001^{a}$ \\
\hline Non-ischemic CM & $1,216(48.2)$ & $585(49.7)$ & $631(47.0)$ & 0.1797 \\
\hline NYHA Class III & $760(30.2)$ & $301(25.6)$ & $459(34.2)$ & $<0.0001^{\mathrm{a}}$ \\
\hline $\begin{array}{l}\text { EF Mean (Std } \\
\text { Dev) }\end{array}$ & $23.8(6.9)$ & $24.5(6.7)$ & $23.2(7.1)$ & $<0.0001^{b}$ \\
\hline $\begin{array}{l}\text { Pulmonary } \\
\text { disease }\end{array}$ & $480(19.0)$ & $195(16.6)$ & $285(21.2)$ & 0.0029 \\
\hline Never smoker & $646(25.6)$ & $315(26.7)$ & $331(24.7)$ & 0.0799 \\
\hline Hyperlipidemia & $1,329(52.8)$ & $645(54.8)$ & $684(51.0)$ & 0.0602 \\
\hline Hypertension & $1,400(55.5)$ & $610(51.8)$ & $790(58.8)$ & 0.0004 \\
\hline Stroke & $166(6.6)$ & $65(5.5)$ & $101(7.5)$ & 0.0431 \\
\hline Diabetes & $767(30.4)$ & $316(26.8)$ & $451(33.6)$ & 0.0002 \\
\hline $\begin{array}{l}\text { Episode of } \\
\text { spontaneous } \\
\text { NSVT }\end{array}$ & $583(23.1)$ & $236(20.0)$ & $347(25.9)$ & 0.0005 \\
\hline Syncope & $162(6.4)$ & $87(7.4)$ & $75(5.6)$ & 0.0658 \\
\hline $\begin{array}{l}\text { QRS duration } \\
<120\end{array}$ & $1,487(59.0)$ & $691(58.7)$ & $796(59.3)$ & 0.7384 \\
\hline $\begin{array}{l}\text { Atrial fibrillation } \\
\text { by ECG }\end{array}$ & $173(6.9)$ & $71(6.0)$ & $102(7.6)$ & 0.1191 \\
\hline $\begin{array}{l}\text { Blood pressure - } \\
\text { diastolic }\end{array}$ & $71.1(11.4)$ & $71.3(11.1)$ & $70.9(11.7)$ & 0.3933 \\
\hline $\begin{array}{l}\text { Blood pressure - } \\
\text { systolic }\end{array}$ & $119.7(19.5)$ & $120.3(19.5)$ & $119.1(19.5)$ & 0.1204 \\
\hline
\end{tabular}




\begin{tabular}{lllll} 
Pulse & $74.7(13.8)$ & $74.0(14.1)$ & $75.3(13.6)$ & 0.0171 \\
Sodium & $139.1(3.3)$ & $139.3(3.1)$ & $138.9(3.5)$ & 0.0054 \\
Potassium & $4.4(0.5)$ & $4.4(0.5)$ & $4.4(0.5)$ & 0.9026 \\
Ace inhibitor & $2,133(84.6)$ & $992(84.2)$ & $1,141(85.0)$ & 0.6033 \\
Beta blocker & $1,738(68.9)$ & $817(69.4)$ & $921(68.6)$ & 0.6740 \\
Digoxin & $1,755(69.6)$ & $802(68.1)$ & $953(71.0)$ & 0.1168 \\
Diuretic (loop) & $2,064(81.9)$ & $936(79.5)$ & $1,128(84.0)$ & 0.0032 \\
Spironolactone & $484(19.2)$ & $202(17.2)$ & $282(21.0)$ & 0.0143 \\
Statins & $965(38.3)$ & $487(41.3)$ & $478(35.6)$ & 0.0030 \\
Months from & $42.5(48.8)$ & $40.0(47.5)$ & $44.63(49.8)$ & 0.0183 \\
CHF diagnosis to & & & & \\
enrollment & & & & \\
(CHFDXMO) & & Continuous & Continuous & Continuous \\
Continuous & Continuous & variables are & variables are & variables are \\
variables are & variables are & represented as & represented as & represented as \\
represented as & represented as & mean $( \pm \mathrm{SD}) ;$ & mean $( \pm \mathrm{SD}) ;$ & mean $( \pm \mathrm{SD}) ;$ \\
mean $( \pm$ SD); & mean $( \pm \mathrm{SD}) ;$ & categorical & categorical & categorical \\
categorical & categorical & variables as n & variables as n & variables as n \\
variables as n & variables as n & $(\%)$. & $(\%)$. & $(\%)$. \\
$(\%)$. & $(\%)$. & & & \\
\hline
\end{tabular}

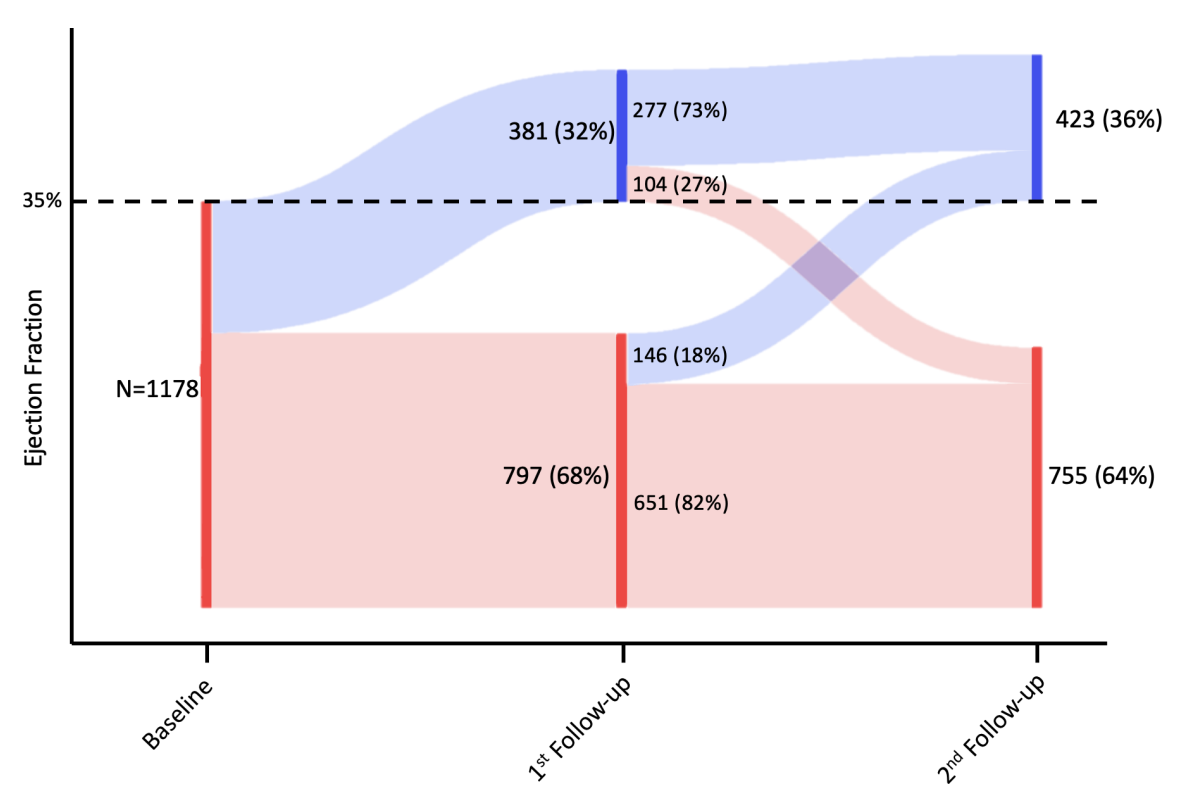




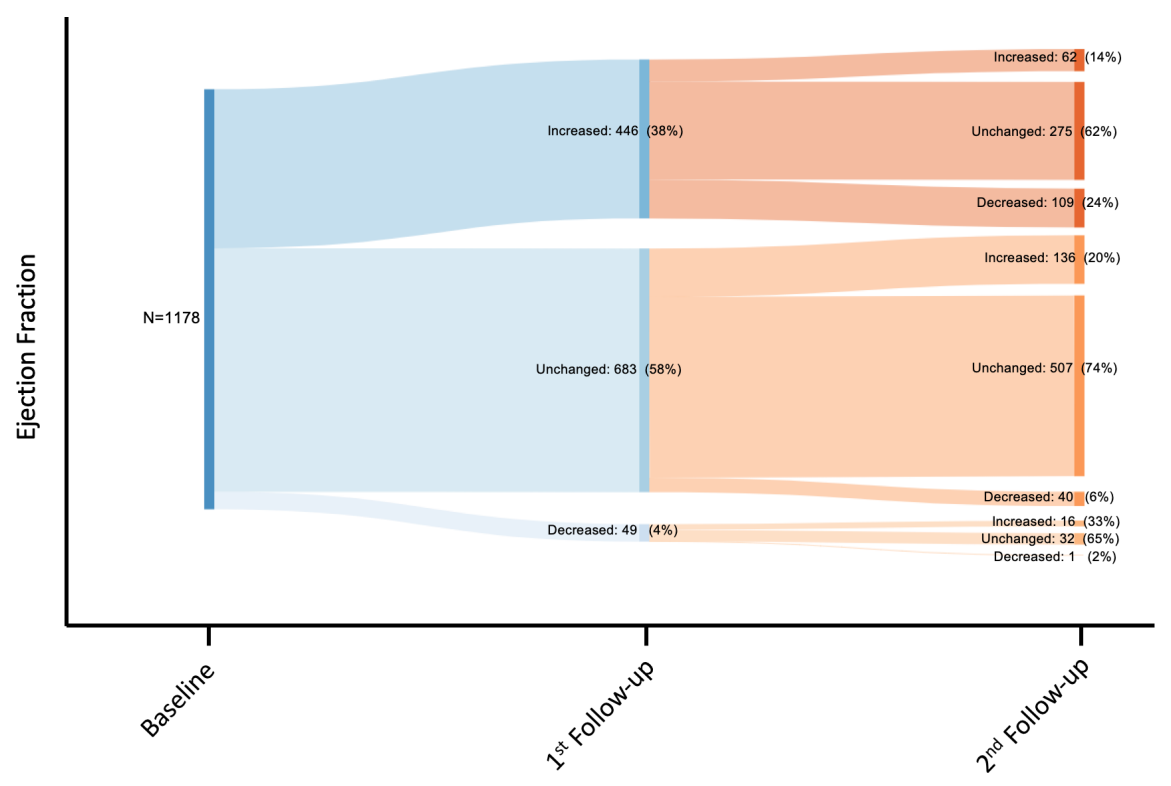

